\title{
The Importance of Providing Psychotherapy Services to Homebound Seniors
}

\author{
Angela L Lewis* and Michael W Brand \\ Department of Psychiatry and Behavior Sciences, University of Oklahoma Health Sciences Center, USA
}

*Corresponding author: Angela L Lewis, Department of Psychiatry and Behavior Sciences, University of Oklahoma Health Sciences Center, 920 Stanton L Young, PO Box 26901, OKC OK 73126-0901, USA

Submission: 眥 May 11, 2018; Published: 笽 May 14, 2018

\section{Opinion}

In 2015, the Census Bureau calculated that individuals age 65 and older make up $14.9 \%$ of the population, 47.8 million people (www.census.gov). These "seniors" are the fastest growing population in the United States. According to census.gov, people are living longer, and many of those people are living alone. The census bureau predicts that there will be more people over the age of 65 than there are young adults by the middle of the next century. As the rate of the homebound seniors continues to increase, the need for home-based services will continue to escalate.

Seniors suffer from a multitude of mental health issues. For example, depression may affect as much as $20 \%$ of seniors, especially those who are homebound and cannot leave their home without assistance of another person. Many adult mental health disorders go unreported, most notably in those adults who remain homebound. Some of the more common senior adult mental health disorders are depression, anxiety, cognitive impairment, and substance abuse. The challenge of these mental health issues in older adults are often exacerbated by co-morbid disorders, both mental and physical. In the elderly, untreated depression has negative effects on all aspects of life, including physical functioning, quality of life, and ability to adapt to illness. Further, untreated mental illness is associated with increased death rates, higher health care costs, less satisfaction with care, and noncompliance with treatment [1].

The idea of home-based services is not a new concept, but it is certainly a much-needed one. The initial concept of providing homebound services to individuals originated in the early nineteenth century. The Charity Organization Society (COS) recruited volunteers to visit the homes of the poor in order to complete assessments to determine needed services. Volunteers went into the homes to conduct these assessments, and provided guidance and direction to these individuals. The hope was that counseling provided would help those living in poverty to change their behaviors [2]. These friendly visitors gave rise to the settlement house movement and to social work as an emerging profession. Jane Addams, the "mother of social work", was a part of the settlement house movement and advocated for the home-based visits for the poor and for peace.

By the middle of the twentieth century, home-based services had become more frequent. However, in recent years, homebased services have decreased due to the lack of funding and the unwillingness of some providers to go into the home. This is an unfortunate outcome, as home-based mental health services and intervention can have several benefits. For example, home-based services may reduce feelings of anxiety and shame that could be associated with seeking treatment (Geriatric Mental Health and the Concept of In- Home Psychotherapy, 2007).

The positive effects of home-based services are well established. In 1992, Muijen et al. [3] (Home Based Care and Standard Hospital Care for Patients with Severe Mental Illness: A Randomized Controlled Trial. 304, 749-754) reported an 80\% reduction in hospital stays in their study conducted in the United Kingdom. Since then, many researchers have found positive clinical outcomes associated with home-based mental health services. In a randomized controlled trial of a home-based mental health treatment, Program to Encourage Active, Rewarding Lives for Seniors (PEARLS), and usual care, the PEARLS program significantly reduced depression and improved the quality of participants' lives [1]. Furthermore, the Veterans Administration has begun integrating home-based mental health services by adding mental health provides to their wellestablished Home Based Primary Care (HBCP) teams. These mental health providers address the full range of mental health problems from grief to substance abuse, to include PTSD and chronic pain, in context of primary care provided in the veteran's home. In addition, Reifler \& Bruce [4] reported that there is serious unmet need for in-home care, there are a number of successful home-based models from which to choose, and that funding for home-based care can come from a number of sources.

There are many reasons why a senior may be homebound. Some may remain in their homes because of mental and/or physical 
health reasons. Others may simply lack transportation. Homebound seniors may be non-ambulatory or suffer from other physical ailments that prevent them from easily leaving their homes. Some may not have adequate financial resources.

Regardless of the reason, recognizing the importance of being able to provide mental health services to homebound seniors must be addressed. Egger postulated that home visits could reduce admissions to the hospitals and nursing homes, and may even prevent loss of life. Being homebound can often lead to more serious mental health issues, such as agoraphobia or dementia and depression is known to occur at higher rates among those who are homebound [1]. Medicare considers seniors homebound if

A. They require the help of another person or medical equipment to leave their home or their doctor believes a senior's health could deteriorate if she or she leaves home, and

B. It is difficult for them to leave their homes (www. medicareinteractive.org).

Home-based therapy allows for a more relaxed and affable session [2]. In this setting, the social work can obtain a more comprehensive picture of the individual and/or family in the home, their environment, and their neighborhood. The social worker providing therapy may be the only person from the community allowed into the home. Thus, it is important to pay attention to visual cues that may help determine whether the patient has adequate nutrition, whether they are well cared for by family members, and to ensure that there are no signs of abuse and/or neglect. According to Cohen [5], the global view of the patient is only apparent when the provider steps into the patient's environment and looks at things from the patient's point of view [6].

Informed consent is another part of therapy, whether in the office or in the home. Seniors must know their rights and therapists must make known their own responsibilities in regards to planned interventions. Every person has the right to know the standard care of care and the recommended treatment they will receive and the associated benefits and risks. Informed consent should be a continual conversation that takes place throughout the therapeutic process, not a one-time conversation. As always, the therapist must be mindful of the patients' rights to self-determination and human dignity (nih.gov).

Psychotherapy in the home of senior citizens just makes sense. Since the beginning, social workers have focused on the relationship between people and their environments Cohen [5]. Being in the home allows the social worker to experience the patient's surroundings and obtain a clearer picture of the senior This approach can also provide the therapist with an unambiguous representation of the environmental conditions in the home and how the family functions as a whole unit [6]. Additionally, the home is often less threatening and formal than an office setting and allows for a day more relaxed therapy session. A senior might feel more at ease to talk about traumatic experiences when they are in their own environment. In addition [7], home-based services can minimize feelings of isolation and can provide much-needed services for the homebound senior

Many years ago, social work was cultivated from the right to self-determination, ownership over personal decisions, privacy, and autonomy. Home visits afford us the chance to better understand the patients we serve and it gives the senior a chance to have much needed services $[8,9]$. Reaching out for help may seem impossible for someone who is homebound. If homebound services were more obtainable for seniors, seeking help might not seem like such of a daunting task. Psychotherapy is a helpful tool, and should be an option for everyone, including the seniors who need it most, our homebound seniors $[10,11]$.

\section{Acknowledgement}

The Authors gratefully acknowledge Ms Kathy J Kyler Staff Editor at the University of Oklahoma Health Sciences Center for her editorial input.

\section{References}

1. Ciechanowski P, Wagner E, Schmaling K, Schwartz S, Williams B, et al. (2004) Community integrated home based depression treatment in older adults: : a randomized controlled trial. JAMA 291(13): 1569-1577.

2. Weiss H (1999) Home Visits: Necessary but Not sufficient. The Future of Children 3(3): 113-128.

3. Muijen M, Marks I, Connolly J, Audini B, Neilson G, et al. (1992) Informed consent to treatment in psychiatry. ncbi.nlm.nih.gov

4. Reifler BV, Bruce ML (2014) Home based mental health services for older adults: a review of ten model programs. Am J Geriatr Psychiatry 22(3): 241-247.

5. Cohen SN, Egen B (1981) The Social work home visit in a health care setting, social work in health care 6(4):

6. Lane CE (2007) Geriatric mental health and the concept of in home psychotherapy.

7. Egger M (2001) Commentary: When, Where, and Why Do Preventative Home Visits Work? BMJ 323:

8. Karlin BE, Karel MJ (2013) National integration of mental health providers in va home based primary care: an innovative model for mental health care delivery with older adults. The Gerontologist 54(5): 868-879.

9. Kayman DJ (2012) Depression in homebound older adults: recent advances in screening and psychosocial interventions. Interdisciplinary Studies in Geriatric Mental Health.

10. Axelrod T (1978) Innovative roles for social workers in home care programs. Health and Social Work 3: 49-66.

11. Bull Schweiz Akad Med Wiss (1980) The dignity and rights of patients NIH 36(4-6): 235-247. 
Creative Commons Attribution 4.0 International License

For possible submissions Click Here

GGS | Gerondonge 2

\section{Gerontology \& Geriatrics Studies}

Benefits of Publishing with us

- High-level peer review and editorial services

- Freely accessible online immediately upon publication

- Authors retain the copyright to their work

- Licensing it under a Creative Commons license

- Visibility through different online platforms 